\title{
SÍNDROME HEMOFAGOCÍTICO O LINFOHISTIOCITOSIS HEMOFAGOCÍTICA POR VIRUS EPSTEIN BARR
}

\author{
HEMOPHAGOCYTIC SYNDROME HEMOPHAGOCYTIC LINFOHYSTIOCYTOSIS BY EPSTEIN BARR VIRUS
}

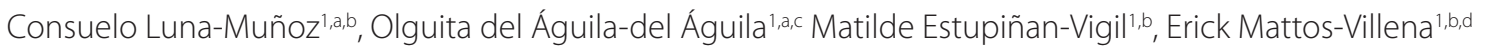

\section{RESUMEN}

Niña de dos años y 10 meses de edad con fiebre, citopenia, hipertrigliceridemia, hipofibrinogenemia y ferritinemia. Tiene mielograma con hemofagocitosis, se identifica virus de Epstein Barr. Paciente evoluciona desfavorablemente, ingresa a ventilación mecánica y fallece.

Palabras clave: Sindrome hemofagocítico; Linfohistiocitosis hemofagocítica; Virus de Epstein Barr; Niños (fuente: DeCS BIREME).

\begin{abstract} bly, enters mechanical ventilation and dies. (source: MeSH NLM).

\section{INTRODUCCIÓN}

El síndrome hemofagocítico $(\mathrm{SH})$ o linfohistiocitosis hemofagocítica (LHH) es un trastorno poco frecuente del sistema inmunitario que afecta principalmente a lactantes y niños pequeños, aunque puede desarrollarse por primera vez a cualquier edad ${ }^{1}$. Se caracteriza por una activación inmune patológica, que es resultado de la disfunción de las células natural killer (NK) que lleva a sobreestimulación, proliferación y migración ectópica de células T y se presenta con signos y síntomas de inflamación excesiva ${ }^{2}$.
\end{abstract}

Two-year, 10-month-old girl with cytopenia fever, hypertriglyceridemia, hypo brinogenemia, and ferritinemia. It She has myelogram with hemophagocytosis, Epstein Barr virus is identified. Patient evolves unfavora-

Key words: Hemophagocytic syndrome; Hemophagocytic lymphohistiocytosis, Epstein Barr virus; Children

La incidencia es 1.2 casos/millón /año, sin embargo hay muchos pacientes hoy en día que no son diagnosticados ${ }^{2,3}$.

La fiebre de origen desconocido, citopenias, esplenomegalia, hipofibrinogenemia, hipertrigliceridemia y/o hemofagocitosis son las principales manifestaciones clínicas del SH o $\mathrm{LHH}^{2,3}$.

Tiene dos formas de presentación, la hereditaria (primaria) y la adquirida (secundaria) ${ }^{2}$.

A continuación presentamos el caso de una niña de

\footnotetext{
${ }^{1}$ Hospital Nacional Edgardo Rebagliati Martins, Lima-Perú.

a Médico Cirujano.

b Especialista en Pediatría.

cPediatra Infectóloga.

'Subespecialista en Hematología Pediátrica.
}

Correspondencia: Consuelo Luna Muñoz. Dirección: Av. Edgardo Rebagliati № 490. Jesús María 15072, Lima, Perú. Teléfono: (01) 2654901. Correo: Iuna_consuelo@yahoo.es 
2 años y 10 meses con síndrome hemofagocítico (SH) o linfohistiocitosis hemofagocítica $(\mathrm{IHH})$.

\section{REPORTE DE CASO}

Paciente mujer de 2 años 10 meses, procedente de Lima, antecedente de exantema súbito a los 9 meses de edad y varicela al año de edad, con vacunas completas (esquema nacional), niegan hospitalizaciones previas. Ingresa por emergencia pediátrica casi iniciando la segunda semana de enfermedad (sexto día) con síndrome mononucleósido (fiebre, faringitis y adenomegalias), hepatitis colestásica (hepatomegalia de $4 \mathrm{~cm}$ ), hiporexia, malestar general, vómitos, dolor abdominal y edema bipalpebral y generalizado (blando, que no deja fóvea).

Al quinto día de hospitalización presenta rash máculo papular en abdomen y miembros inferiores, persiste con citopenia. Al sexto día, se agrega hipertrigliceridemia, hipofibrinogenemia e hiperferitonemia y se plantea el diagnóstico de síndrome hemafagocítico. Al sétimo día evoluciona a falla hepática aguda y al octavo día informan mielograma con hemofagocitosis. Inician protocolo especifico de inducción (dexametasona, etoposido y ciclosporina A. Paciente recibe amplia cobertura antibiótica (ceftazidime, vancomicina, clindamicina), también con aciclovir. Con el trascurso de los días la evolución de la paciente es desfavorable, a los 16 días de hospitalización cursa con encefalopatía hepática, insuficiencia respiratoria, es conectada a ventilación mecánica y a los 22 días de hospitalización constatan fallecimiento.

\section{EXÁMENES DE LABORATORIO}

\section{Primer día de hospitalización}

- $\quad \mathrm{Hb} 10.2$ g/dl, Leu 5300 neu 535 linf 3482 y linfocitosis activos, trombocitopenia $(83,000 \mathrm{u} / \mathrm{l})$

- Perfil de coagulación: Tiempo de protombina 13.10 seg. (10-13), INR 1.12 (0.85-1.15), Tiempo de tromboplastina $34 \mathrm{seg}$. (25-37). Fibrinógeno $123.2 \mathrm{mg} / \mathrm{dl}(200-400)$

- Perfil hepático alterado: TGO 878 UI/L, TGP 516 $\mathrm{UI} / \mathrm{L}$ (0-41), BT $5.01 \mathrm{mg} / \mathrm{dl}$ (0.1-1.2), BD $3.54 \mathrm{mg} /$ dl (0-0.5) Bl $1.47 \mathrm{mg} / \mathrm{dl}$ (0-0.5), FA $1619 \mathrm{U} / \mathrm{L}$ (0300), LDH 2901, U/L (240-480)

- Sedimento urinario con pigmentos biliares positivo
- $\quad$ PCR alterado $4.73 \mathrm{mg} / \mathrm{dl}(0-0.5)$.

\section{Sexto día de hospitalización}

- Hb 8.8 g/dl, Leu 2960 neu 132 linf 726, plaquetas $146,000 \mathrm{u} / \mathrm{l}$.

- Perfil hepático alterado:TGO 768 UI/L, TGP 1279 $\mathrm{UI} / \mathrm{L}(0-41), \mathrm{BT} 8.41 \mathrm{mg} / \mathrm{dl}$ (0.1-1.2), BD $5.91 \mathrm{mg} /$ dl (0-0.5), FA 2825 U/L (0-300), LDH 2901 U/L (240-480), Albúmina $2.8 \mathrm{~g} / \mathrm{dl}$ (3.4-4.8).

- Triglicéridos 709mg/dl (60-200).

- Ferritina $19999.00 \mathrm{ng} / \mathrm{ml}$ (5-148).

\section{Sétimo dia de hospitalización}

- Fibrinógeno 70 mg/dl (200-400).

- Ferritina $19999.00 \mathrm{ng} / \mathrm{ml}$.

- Serología VEB: VCA IgM y VCA IgG positivos.

- Carga viral de EBV: 130,000 copias /ml.

\section{ULTRASONIDO ABDOMINAL}

Al inicio leve hepatomegalia y ascitis leve, a los 12 días de hospitalizada hepatoesplenomegalia, ascitis abdominopélvico tabicada, hematoma en pared abdominal en región periumbilical izquierda y leve efusión pleural derecha.

Entre las complicaciones agudas y graves con riesgo de muerte que pueden presentar los pacientes con mononucleosis infecciosa se encuentra el SH o LHH desencadenado por VEB Barr ${ }^{4,5}$.

El SH o LHH se describe por primera vez en 1939, caracterizado por fiebre, adenopatías, pancitopenia y proliferación histiocítica en la médula ósea ${ }^{6}$.

Los síndromes hemofagocíticos o LHH se caracterizan por presentar un defecto en la contracción y una expansión continua e ilimitada de la respuesta inmunitaria'.

Tiene dos formas de presentación, la hereditaria (primaria) es de herencia autosómica recesiva y la adquirida (secundaria).

Además de las formas familiares, la LHH primaria se asocia a inmunodeficiencias, cuya evolución puede ser fulminante, sobre todo si el desencadenante es la infección por el virus de Epstein-Barr (VEB) ${ }^{1}$. La presentación más frecuente de LHH secundaria se asocia a infecciones (virus, bacterias, hongos y parásitos) ${ }^{7}$, también aparece en el contexto de neoplasias malignas, tratamiento con fármacos inmunosupresores de aplicación prolongada y trastornos metabólicos, su frecuencia es mayor que la presen- 
tación primaria'. La paciente presentó SH o LHH asociado a infección viral, en este caso se identificó el virus de Epstein Barr, que es la infección asociada más frecuente ${ }^{2,3}$.

El síndrome de activación de macrófagos es una variante de las formas secundarias, se asocia a enfermedades autoinmunes ${ }^{3}$.

Tabla 2. Formas de síndrome hemofagocítico (Kumakura 2005).

\section{Primaria}

Linfohistiocitosis hemofagocítica familiar (4 subtipos: LHF 1-4).

\section{Secundarias}

Infecciones

Víricas: Citomegalovirus, virus herpes, adenovirus, parvovirus, coxsackie, virus Epstein Barr, VIH, varicala zoster, hepatitis A, B y C.

Bacterianas: Salmonella, enterobacterias, Rickettsia coronii, Mycobacterium tuberculosis Mycoplasma pneumoniae, Coxiella burnetti, espiroquetas (leptospira spp, Treponema pallidum).

Parasitarias: Leishmania spp, Plasmodiun falciparum, Toxoplasma gondii, Babesia microti.

Fúngicas: Aspergillus, Histoplasma capsulatum, Candida albicans, Cryptococcus neoformans.

Enfermedades autoinmunitarias

Artritis reumática juvenil idiopática, Lupus eritematoso sistémico, paniculitis histiomacroesofágica.

Enfermedades malignas

Leucemias o Linfomas T o NK, tumores germinales mediastinales.

Fármacos

Emulsiones lipidicas de nutrición parenteral, sales de oro, sala-

zopirina, ácido acetilsalicílico, indometacina.

Los niños se consideran población susceptible para VEB y citomegalovirus (CMV), ambos virus son oportunistas en el paciente inmunocomprometido, además, se infectan con virus de Ebstein Barr (VEB) en la lactancia y primera infancia ${ }^{4,5,8}$ la infección es más frecuente en niños de bajo nivel socioeconómico y de países en vías de desarrollo, en este grupo la infección es generalmente leve, asintomática o atípica $^{8}$. La paciente según historia clínica era inmunocompetente, no era de nivel socioeconómico bajo, evolucionó a SH o LHH y falleció.

SH o LHH se caracteriza por presentar fiebre prolongada, citopenia, esplenomegalia, hepatomegalia, hemofagocitosis, hipertrigliceridemia e hipofibrinogenemia, además suele acompañarse también con coagulopatía e hiperferritinemia, comprende manifestaciones inflamatorias sistémicas semejantes a la sepsis 9 . La mayoría de los pacientes tienen evidencia variable de hepatitis al inicio ${ }^{2}$. Nuestra paciente presentó todas estas manifestaciones clínicas y laboratoriales.

Reportan que la fiebre y esplenomegalia están presentes en el $75 \%$ de los pacientes al momento del diagnóstico y sólo en la mitad de los casos la bicitopenia, hipertrigliceridemia y ferritina $>500 \mathrm{ng} / \mathrm{ml}^{3}$.

Tabla 1. Criterios diagnósticos del síndrome hemofagocítico.

Enfermedad familiar o defecto genético conocido de SH familiar, o presentar 5 de los 8 siguientes

Fiebre $\geq 38,5^{\circ} \mathrm{C}$

Esplenomegalia

Citopenia que afecte a 2 o más series $(\mathrm{Hb}<9 \mathrm{~g} / \mathrm{dL}$ [niños $<4$ semanas, $\mathrm{Hb}<10 \mathrm{~g} / \mathrm{dL}$ ], plaquetas $<100.000 / \mu \mathrm{L}$, neutrófilos $<1.000 / \mu \mathrm{L}$ )

Hipertrigliceridemia ( $>265 \mathrm{mg} / \mathrm{dL}$ ) y/o hipofibrinogenemia $(<150 \mathrm{mg} / \mathrm{dL})$

Hemofagocitosis en médula ósea, bazo, hígado o ganglios, sin evidencia de malignidad

Actividad citotóxica de células NK baja o ausente

Hiperferritinemia ( $>500 \mathrm{ng} / \mathrm{mL}$ )

CD25 soluble elevado (sIL-2R $>2.400 \mathrm{U} / \mathrm{mL}$ )

Fuente: $\mathrm{HLH}-2004$, en Janka2.

De los 8 criterios mencionados en la tabla 1, la paciente cumple 6 criterios diagnósticos propuestos por la Histiocyte Society.

En la literatura reportan otras manifestaciones clínicas, que son menos frecuentes, adenopatías, rash, edemas e ictericia ${ }^{3}$, nuestra paciente si las presentón ${ }^{2,3}$.

Los hallazgos histológicos del SH o LHH, que se encuentran en la biopsia de medula ósea, ganglios linfáticos y bazo son las células hemofagocíticas ${ }^{2,10}$. En nuestro caso se confirmaron estas células tanto en el frotis de sangre periférica como en el aspirado de médula ósea.

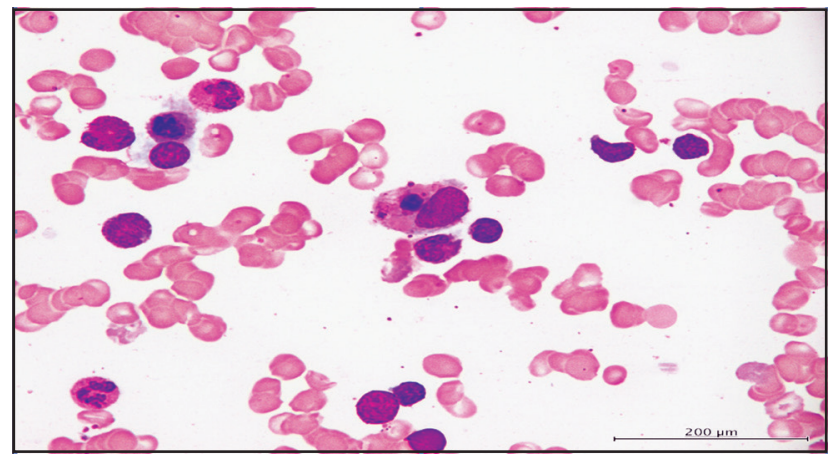

Figura1. Se observa macrófagos activados y Hemofagocitosis (fagocitosis de eritrocitos, plaquetas y mielocitos), células plasmáticas ocasionales. 
En conclusión, sospechar SH o LHH en presencia de fiebre prolongada, citopenias, esplenomegalia, hipertrigliceridemia, hipofibrinogenemia y/o hemofagocitosis en médula ósea, ganglios linfáticos y bazo, realizar diagnóstico precoz para inicio de tratamiento específico, la mortalidad es alta.
Financiamiento: Autofinanciado.

Conflicto de interés: Los autores declaran no tener conflicto de interés en la publicación de este artículo.

Recibido: 05 de Julio 2016

Aprobado: 09 de Agosto 2016

\section{REFERENCIAS BIBLIOGRÁFICAS}

1. Pérez A. Síndromes hemofagocíticos (I): concepto, clasificación, fisiopatología y clínica. An Pediatr Contin. 2013;11(5):237-442.

2. Izaguirre-González A, Sánchez-Sierra LE, A. Cerrato-Castro A, J Flores-Irías A. Peña A. Síndrome Hemofagocítico Reactivo en Lactante Mayor. Reporte de Caso. Archivos de Medicina ISSN 1698-9465. 2016;12(3):16 doi:10.3823/1315.

3. Bautista EKA, Fossas GP, Rodríguez LE. Síndrome hemofagocítico. Conceptos actuales. Gaceta Médica de México.2013;149:431-437.

4. Wang X, Yang K, Wei C. Coinfection with EBV/CMV and other respiratory agents in children with suspected infectious mononucleosis. Virol J. 2010;247.

5. Luzuriaga K, Sullivan J. Infectious Mononucleosis. N Engl J Med. 2010;362:1993-2000.
6. Scott R, Robb-Smith A. Histiocytic medullary reticulosis. Lancet. 1939;2:194-8Risma K, Jordan MB. Hemophagocytic lymphohistiocytosis: updates and evolving concepts. Curr Opin Pediatr. 2012;24:9-15.

7 Fisman DN. Hemophagocytic syndromes and infection. Emerg Infect Dis. 2000;6:601-8.

8. Martín J, Lázaro J. Mononucleosis infecciosa en la infancia Pediatr Integral 2014;18(3):141-152

9. Kleinert MM, Garate G, Osatnik J, Cicco J, Hunter B, Soria EJ. Síndrome hemofagocítico reactivo en pacientes graves. Comunicación de 4 casos. Medicina (B. Aires). 2007;67(1).

10. Dubuc ECA, Ecenarro UM, Villalba MC, Cáceres AV, Rubio HN, et al. Síndrome hemofagocítico como manifestación clínica inicial del lupus eritematoso sistémico. Reumatol Clin. 2014;10:321-324.

\section{Consulte la Revista:}

Facultad de Medicina Humana Universidad Ricardo Palma

Desde nuestro nuevo código QR

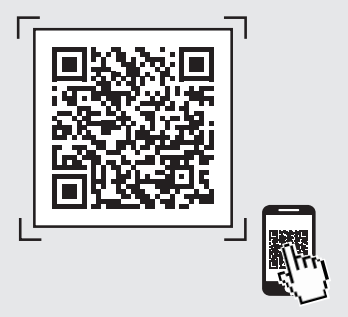

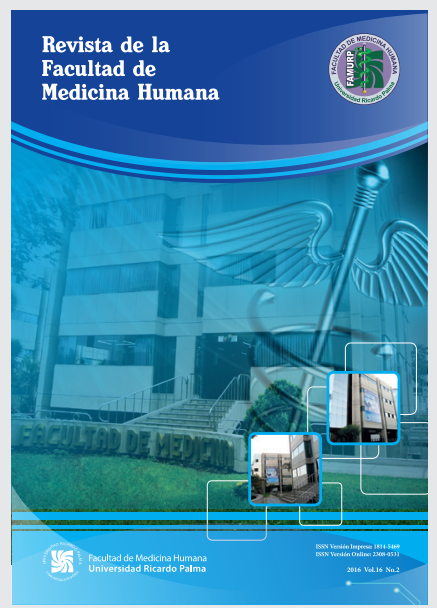

